Editorial

\title{
Significant of serum 25-hydroxyvitamin D and thyroid hormones levels in pregnant women in Jordan
}

\section{Editorial}

Maternal Vitamin D deficiency is widespread health problem. Many studies showed the role of Vitamin D and thyroid hormones levels in pregnant women ${ }^{1}$ however, fluctuation of Vitamin D level in pregnant women especially those wearing Hejab can cause serious problem due to minimal body exposure to sun light. Calcium level depleted in pregnant women and required vitamin $\mathrm{D}$ level is important for the demand of calcium from the fetus, since calcium is needed significantly for fetus growth and bone development. ${ }^{2,3}$ Vitamin D is also needed in healthy pregnancy for fetus skeletal development and to prevent any neurological disorder, also it is essential in fetal immune. Vitamin D deficiency during pregnancy has been linked to number of health problems in offspring. ${ }^{3}$ It is known that Vitamin D has direct influence on molecular pathways and hence it is important in the pathogenesis of preeclampsia ${ }^{3,4}$ and bone development in fetus is linked to a steroid hormone in the form the 25-hydroxyvitamin $\mathrm{D}(25(\mathrm{OH}) \mathrm{D})$ which introduced in the body by food intake with sufficient supplement of Vitamin D however, the major source of vitamin $\mathrm{D}$ is through the skin synthesis through exposure to solar ultraviolet light $(\mathrm{UVB})^{5}$ in the range of $280-320 \mathrm{~nm}$ which can penetrate skin and promote conversion of 7dehydrocholesterol to provitamin D3 (cholecalciferol) in the skin coupled with oral intake that is less what needed during pregnancy. ${ }^{3}$ Despite the source of Vitamin $\mathrm{D}$ the final conversion occurs in the liver to maintain the level of 25 -hydroxyvitamin D in the body. The $25(\mathrm{OH}) \mathrm{D}$ is metabolized in the kidneys by the enzyme 25-hydroxyvitaminD-1a-hydroxylase (CYP27B1) to active form 1,25-dihydroxyvitamin $\mathrm{D}^{1}$ this product is tightly regulated by plasma levels parathyroid hormone, calcium and phosphorus levels. ${ }^{6}$ Vitamin D concentration $>30.0 \mathrm{ng} / \mathrm{ml}$ $(>75,0 \mathrm{nmol} / \mathrm{L}$ considered to be sufficient, insufficient level is between 20 and $30 \mathrm{ng} / \mathrm{mL}(50-75 \mathrm{nmol} / \mathrm{L})$ and deficient if it is $<20 \mathrm{ng} / \mathrm{mL}$ $(<50 \mathrm{nmol} / \mathrm{L}))^{7,8}$ There are many factors influence Vitamin D levels in the body such as geographical zones, dietary patterns, physical environment, seasons, dark skin pigmentation and obesity., ${ }^{9,10}$

The role of thyroid in the body is essential for developing healthy fetus. ${ }^{11}$ The role of placental extrogen as stimulus for Thyroxine Binding Globulin (TBG) synthesis is well known. The hypothalamic hormone stimulates the synthesis of the two thyroid hormones T3 (triiodothyronine) and T4 (Thyroxine Binding Globulin). Thyroid hormones stimulate intrauterine growth, especially during the second half of gestation and they have an impact on fetal metabolism. ${ }^{1}$ Many studies have shown the probable role of vitamin D in autoimmune thyroiditis and pathogenesis of autoimmune thyroid disease (AITDs) in non-pregnant women, however, the role of $25(\mathrm{OH}) \mathrm{D}$ in association with thyroid hormones in pregnancy is of great concern particularly in region with high source of sunlight and less exposure.

The aim of this editorial is to illustrate the significant of Vitamin D in correlation to Thyroid hormones status (TSH, T4, T3) in pregnant women, especially those wearing Hejab in Jordan due to the fact that
Volume 3 Issue I - 2016

\author{
Mohammed Nizar Battikhi \\ Battikhi Central Laboratory Amman, Jordan \\ Correspondence: Mohammed Nizar Battikhi, 1017-1645 De \\ Maisonneuve Boulevard, west Montreal (Quebec) H3H 2N3, Tel \\ 5|4-933-56|3, Email m_nizar I @@hotmal.ca
}

Received: January 06, 2016 | Published: January 07, 2016

Hejab reduce exposure to sunlight. Therefore this editorial will lay out future proposal study for measuring Vitamin D and thyroid hormones levels in pregnant women wearing Hejab compared to placebo groups with higher sun light exposure in order to update their dietary supplement for Vitamin D deficiency.

\section{Acknowledgments}

None.

\section{Conflicts of interest}

Author declares that there is no conflict of interest.

\section{References}

1. Lavalle G, Onori ME. Relationship between Serum 25-Hydroxyvitamin $\mathrm{D}$ and Thyroid Hormones during Pregnancy in Italy. International Journal of Science and Research (IJSR). 2014;3(10):358.

2. Pérez-Lopéz FR (2007) Vitamin D: the secosteroid hormone and human reproduction. Gynecol Endocrinol 23(1):13-24.

3. Bodnar LM, Catov JM, Simhan HN, et al. Maternal vitamin D deficiency increases the risk of preeclampsia. J Clin Endocrinol Metab. 2007;92(9):3517-3522.

4. Levenson CW, Figueirôa SM. Gestational vitamin D deficiency: longterm effect on the brain. Nutr Rev. 2008;66(12):726-729.

5. Lehmann B, Querings K, Reichrath J. Vitamin D and skin: new aspects for dermatology. Exp Dermatol. 2004;13(suppl 4):5-11.

6. Lips P. Vitamin D and physiology. Prog Biophys Mol Biol. 2006;92(1):4-8.

7. Chailurkit LO, Aekplakorn W, Ongphiphadhanakul B. Regional variation and determinants of vitamin $\mathrm{D}$ status in sunshine-abundant Thailand. BMC Public Health. 2011;11:853.

8. Holick MF. Vitamin D deficiency. N Engl J Med. 2007;357(3):266-281.

9. Karras SN, Anagnostis P, Annweiler C, et al. Maternal vitamin D status during pregnancy: the Mediterranean reality. Eur J Clin Nutr. 2014;68(8):864-869. 
10. Tsiaras WG, Weinstock MA. Factors influencing vitamin D status. Acta Derm Venereol. 2011;91(2):115-124.
11. Lapillonne A. Vitamin D deficiency during pregnancy may impair maternal and fetal outcomes. Med Hypotheses. 2010;74(1):71-75. 